\title{
Spectral-Luminescent Properties of meso-Tetraarylporphyrins Revisited: The Role of Aryl Type, Substitution Pattern and Macrocycle Core Protonation
}

\author{
Irina V. Vershilovskaya ${ }^{\text {a }}$ Stefano Stefani, ${ }^{\mathrm{b}}$ Pieter Verstappen, ${ }^{\mathrm{c}}$ Thien H. Ngo, ${ }^{\mathrm{b}, \mathrm{d} @ 1}$

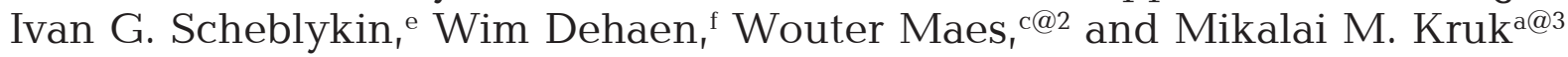 \\ ${ }^{a}$ Belarussian State Technological University, Physics Department, 220006 Minsk, Belarus \\ ' Institut für Chemie und Biochemie, Freie Universität Berlin, 14195 Berlin, Germany \\ ${ }^{c}$ Design \& Synthesis of Organic Semiconductors (DSOS), Institute for Materials Research (IMO-IMOMEC), Hasselt \\ University, B-3590 Diepenbeek, Belgium \\ dinternational Center for Materials Nanoarchitectonics (MANA), National Institute for Materials Science (NIMS), 305-0044 \\ Tsukuba, Ibaraki, Japan \\ 'Lund University, Division of Chemical Physics, 22100 Lund, Sweden \\ ${ }_{\mathrm{f}}$ Molecular Design and Synthesis, Department of Chemistry, KU Leuven, B-3001 Leuven, Belgium \\ ${ }^{\circledR 1}$ Corresponding authorE-mail:krukmikalai@yahoo.com; m.kruk@belstu.by \\ $@^{\circledR 2}$ Corresponding author E-mail: woutermaes@uhasselt.be \\ ${ }^{\circledR 3}$ Corresponding author E-mail:ngo.huynhthien@nims.go.jp
}

\begin{abstract}
Both the ground $\left(S_{0}\right)$ and the lowest singlet excited states $\left(S_{1}\right)$ for a series of 5,10,15,20-tetraarylporphyrins consisting of two symmetrically and four asymmetrically substituted derivatives $\left(A_{4}, A B_{3}\right.$, trans- $A_{2} B_{2}$, cis- $A_{2} B_{2}, A_{3} B$ and $B_{4}$, where $A=$ phenyl and $B=$ mesityl) are studied by absorption and fluorescence spectroscopies. The rotational degree of freedom of the aryl rings is found to play a crucial role in the discrimination between the radiative and radiationless decays of the $S_{1}$ states. This feature is dramatically enhanced upon going from the free base molecules to their monoand diprotonated forms because of the nonplanar macrocycle conformation of the latters. The progressive $A$ to $B$ replacement of the aryl substituents leads to additive spectral changes over the whole series in the free base form. For both mono- and diprotonated species such a gradual additive pattern is broken by a "spectral jump" from the trans to the cis derivative, which is proposed to be a signature of the transition between two macrocycle conformations with different flexibility.
\end{abstract}

Keywords: Porphyrin, meso-substitution, fluorescence, protonation, macrocycle conformation.

\section{Возвращение к спектрально-люминесцентным свойствам мезо-тетраарилпорфиринов: роль типа арильного заместителя, способа замещения и протонирования ядра макроцикла}

\author{
И. В. Вершиловская, ${ }^{a}$ С. Стефрани, ${ }^{\mathrm{b}}$ П. Верстаппен, ${ }^{\mathrm{c}}$ Т. Х. Нго, ${ }^{\mathrm{b}, \mathrm{d} @ 1}$

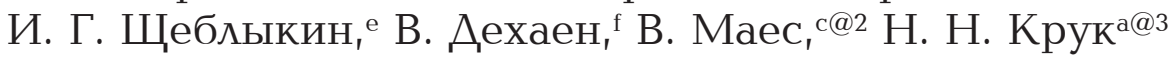
аБелорусский государственный технологический университет, Кафедра физики, 220006 Минск, Беларусь
' Институт химии и биохимии, Свободный университет Берлина, 14195 Берлин, Германия
'Дизайн и синтез органических полупроводников (DSOS), Институт исследования материалов (IMO-IMOMEC), Хассельтский университет, В-3590 Дипенбек, Бельгия
${ }^{\mathrm{d}}$ Международный центр наноархитектоники материалов (МАNA), Нацииональный институт материаловедения (NIMS), 305-0044 Цукуба, Ибараки, Япония
еЛундский университет, Отдел химической физики, 22100 Лунд, Швеция
⿷ Молекулярный дизайн и синтез, Кафедра химии, Лёвенский католический университет, В-3001 Лёвен, Бельгия


@IE-mail:krukmikalai@yahoo.com; m.kruk@belstu.by

${ }^{(22}$ E-mail:wouter.maes@uhasselt.be

${ }^{\circledR 3}$ E-mail:ngo.huynhthien@nims.go.jp

Представлены спектрально-люминесиентные свойства 5,10,15,20-тетраарилпорфиринов - с архитектурой $A_{4}, A B_{3}$, транс- $A_{2} B_{2}$, иис- $A_{2} B_{2}, A_{3} B$ и $B_{4}$ типов ( $A=$ =енил, $B=$ мезитил) - для свободных оснований, моно- и дважды протонированных форм. Для обеих протонированных форм наблюдаются две конформации макрочикла, причем транс- $A_{2} B_{2}$ и иис- $A_{2} B_{2}$ являются пограничными структурами.

Ключевые слова: Порфирин, мезо-замещение, флуоресценция, протонирование, конформация макроцикла.

\section{Introduction}

The family of meso-tetraarylporphyrins, with its most notable example 5,10,15,20-tetraphenylporphyrin or TPP (hereafter referred to as $\mathbf{P h}$ to provide a clear structurerelated notation allowing easy comparison of all compounds studied in this work), gathers the most frequently occurring synthetic porphyrins. These compounds are widely used in the design of artificial models of naturally occurring porphyrin chromophores, ${ }^{[1,2]}$ as key structures of high performance photoactive compounds in dye-sensitized and bulk heterojunction organic solar cells, ${ }^{[3,4]}$ as photosensitizers in photodynamic (cancer) therapy (PDT) and in antibacterial therapy, ${ }^{[5]}$ being the "heart" of a huge diversity of supramolecular systems of different complexity and destination. ${ }^{[1,6]}$ The popularity of 5,10,15,20-tetraarylporphyrins arises from their well-developed and straightforward syntheses and the availability of a wide variety of aryl-functionalized derivatives. ${ }^{[7-9]}$ The vast majority of meso-tetraarylporphyrins carry phenyl-based substituents, although a large number of related compounds is known as well, for example with heteroaryl substituents. ${ }^{[10-15}$ and refs. therein] The meso-aryl rings also provide the possibility for diverse functionalizations, such as substitutions at either the ortho, meta or para positions or quaternization for nitrogen containing heteroaromatic systems. ${ }^{[16,17]}$

It has been speculated for a long time that functionalization on the meso-aryl groups would enable to influence the electronic properties of the porphyrin macrocycle only to a (very) small extent. ${ }^{[18]}$ This hypothesis was based on the idealized model of orthogonal arrangement of the meso-aryl planes with respect to the porphyrin macrocycle mean plane due to steric interactions between the orthohydrogen atoms of the meso-substituents and the hydrogen atoms at the $\beta$-pyrrolic positions of the porphyrin system. Such interaction was expected to prevent the coplanar arrangement of both aromatic $\pi$-systems, disabling significant $\pi$-conjugation between them (if any). The seminal paper of Meot-Ner and Adler unambiguously demonstrated the importance of electronic communication between the porphyrin macrocycle and the meso-phenyl substituents, ${ }^{[19]}$ and initiated a plethora of studies focusing on these electronic interactions. Indeed, the rotational barrier for the phenyl groups was found to be low enough to observe phenyl rotation around the $\mathrm{C}_{\text {meso }}-\mathrm{C}_{\text {ipso }}$ bond at room temperature. ${ }^{[20]}$ Substitution of an ortho-hydrogen atom with a bulkier substituent on at least one of the ortho-positions of the aryl ring prevents this free rotation, and the accessible range for the dihedral angle $q$ between the mean macrocycle and meso-aryl ring planes decreases drastically, ${ }^{[21,22]}$ leading to the formation of atropoisomers for sterically hindered meso-arylporphyrin derivatives. However, even in such a case, non-zero electronic communication between the macrocycle and meso-periphery exists. Both sterical constrains and perturbed electronic communication result in specific spectroscopic consequences, so-called "ortho effects". ${ }^{[23-30]}$

A second wave of studies on meso-tetraarylporphyrins relates to the renewed interest in the diprotonated forms of porphyrins, which arose in the early $90-\mathrm{s}$ and continues up until now, since the diprotonated species are considered as useful model compounds to study the features of nonplanar distortions of tetrapyrrolic macrocycles and their molecular flexibility. ${ }^{[2,31-33]}$ In this framework, essential progress has been achieved in the elucidation of the molecular conformations of diprotonated porphyrins and their relation with the peripheral substitution pattern. ${ }^{[31-35]}$ For meso-aryl substituted porphyrins, it was shown that the degree of saddle-type macrocycle distortion upon formation of the diprotonated form and the decrease in the value of the dihedral angle $q$ are correlated with electronic factors. ${ }^{[35]}$ Saddle-type distortion allows the steric hindrance to be overcome and favors the coplanar conformation of the macrocycle and meso-aryl substituents. in order to relieve the steric repulsion of the inner hydrogen atoms in the macrocyclic core of the diprotonated form, a pyrrole tilting angle (saddling angle) $\varphi$ of $10-15^{\circ}$ is sufficient, ${ }^{[35]}$ but the synergism of the pyrrole ring tilting and aryl group rotation in meso-aryl substituted porphyrins allows the formation of highly distorted conformations with a saddling angle as high as $28-33^{\circ} .{ }^{[10,32]}$ Upon protonation of meso-arylporphyrins with bulky substituents at the orthopositions, both the saddling angle and dihedral angle were found to decrease due to the imposed steric hindrance. ${ }^{[32]}$

5,10,15,20-Tetraphenylporphyrin $\left(\mathbf{P h}_{4}\right)$ and 5,10,15,20tetramesitylporphyrin $\left(\mathbf{M e s}_{4}\right)$ are the prototype representatives of the two extreme cases described above, unhindered and hindered meso-aryl substituted porphyrins. Being almost indistinguishable in their free base (FB) forms, no similarity remains upon protonation of these porphyrins. Whereas the sequential formation of monoprotonated (MP) and diprotonated (DP) species is documented for $\mathbf{M e s}_{4}{ }^{[36]}$ the diprotonated form of $\mathbf{P} \mathbf{h}_{\mathbf{4}}$ appears in a single step involving the simultaneous attachment of two protons, ${ }^{[10]}$ with special efforts needed to stabilize the monoprotonated form. ${ }^{[37]}$ The mechanism of porphyrin basicity control by the meso- 
aryl-substituents has recently been understood with the help of by DFT quantum-chemical calculations and $a b$ initio molecular dynamics simulations. ${ }^{[38]}$ The attachment of the second proton to $\mathbf{P h}_{\mathbf{4}}$ was found to be energetically comparable to the first protonation step, instead of being significantly less favorable as in the case of $\mathbf{M e s}_{4}$. The second proton attachment to $\mathbf{P h}_{\mathbf{4}}$ is facilitated by the interplay between the tilting of the pyrrolenine ring to be protonated and a pronounced electrostatic binding spot at the protonation site (the nitrogen atom of the pyrrolenine ring). Furthermore, the second protonation of $\mathbf{P h}_{\mathbf{4}}$ is particularly eased by the large out of plane flexibility of the diprotonated species, as unraveled by $a b$ initio molecular dynamics simulations. The fluorescence quantum yield $\Phi_{\mathrm{fl}}$ of diprotonated $\mathbf{P h} \mathbf{h}_{4}$ remains about the same as for the free base form, whereas the $\Phi_{\mathrm{ff}}$ value for diprotonated $\mathbf{M e s}_{4}$ is more than two times higher compared to the free base. The dramatic changes in the rates and channels of excitation energy deactivation of diprotonated porphyrins as compared with those for the corresponding free bases and the different mechanisms involved are discussed in a recent review. ${ }^{[36]}$

Structural changes in porphyrins and porphyrin-based supramolecular assemblies related to the meso-aryl substitution pattern are frequently observed. ${ }^{[19-22,31-32,36-38]}$ The synthesis and properties of different series of porphyrin compounds with sequential attachment of meso-aryl groups or the exchange of aryl groups of one type with those of another type have been widely reported. It was shown that the changes of numerous photophysical and physico-chemical properties of the studied meso-arylporphyrins, including the nonlinear two-photon absorption cross section, ${ }^{[39]}$ the molecular contraction upon triplet state formation, ${ }^{[40]}$ the fluorescence quantum yield from the lowest and higher excited states, ${ }^{[36,41-42]}$ the shift of the bands in the absorption spectra, ${ }^{[41-43]}$ and the rates of radiative and nonradiative excitation energy deactivation pathways, ${ }^{[36,41-43]}$ can be interpreted as being "additive" with respect to the number of attached/replaced aryl groups. However, it needs to be stressed that all of these dependencies relate to the porphyrin free bases or metallocomplexes. For these derivatives, the steric hindrance imposed by ortho-substituted meso-aryl groups is minimal (if any). On the contrary, the mono- and diprotonated forms of meso-arylporphyrins reveal a strong interplay between the degree of nonplanar distortions (in the simplest case quantified with a saddling angle $\varphi$ ) and the coplanarity of the mean porphyrin plane and aryl rings (dihedral angle $\theta$ ), as shown above. in this case, the number of sterically hindered and unhindered meso-aryl substituents and the substitution pattern are of high importance for the macrocycle basicity and the photophysical properties of the protonated forms.

Elucidation of the relationship between the sterical hindrances imposed with aryl groups at the macrocycle periphery from one hand, and the spectroscopic properties of meso-substituted porphyrins and meso-porphyrin based dendrimers from other hand, is the subject of our extensive research. ${ }^{[36,38,41-43]}$ Having the aim to go further into the role of the "ortho effect" of aryl substituents we have prepared the series of symmetrical and asymmetrical 5,10,15,20-tetraarylporphyrins with $\mathrm{A}_{4}, \mathrm{AB}_{3}$, trans $-\mathrm{A}_{2} \mathrm{~B}_{2}$, cis $-\mathrm{A}_{2} \mathrm{~B}_{2}, \mathrm{~A}_{3} \mathrm{~B}$ and $\mathrm{B}_{4}$ architecture $(\mathrm{A}=$ phenyl, $\mathrm{B}=$ mesityl) (see structures in Figure 4). In this series, the substitution architecture was used as a tool to modulate the sterical hindrances over macrocycle. Preliminary results of spectroscopic studies with these compounds have been presented recently. ${ }^{[44,45]}$

In this work, we report on the role of rotational degree of freedom of aryl substituents in the discrimination between the radiative and radiationless deactivation of the lowest singlet $\mathrm{S}_{1}$ state of the free bases, mono- and diprotonated forms of studied compounds. The influence of the substitution architecture on the molecular conformation and macrocycle flexibility is uncovered on the basis of the spectrophotometric and spectrofluorometric titration experiments.

\section{Experimental}

Free base 5,10,15,20-tetraphenylporphyrin and 5,10,15,20tetramesitylporphyrin were prepared according to the procedure described by Lindsey and Wagner ${ }^{[46]}$ The series of free base phenylmesityl 5,10,15,20-tetraarylporphyrins was synthesized by mixed $\left(\mathrm{BF}_{3} \cdot \mathrm{OEt}_{2}\right.$ catalyzed) condensation of benzaldehyde and mesitaldehyde (in a 1:1 ratio) with pyrrole (see SI).

UV-Vis absorption spectra were taken by a Perkin-Elmer Lambda 20 spectrophotometer. The fluorescence spectra and fluorescence excitation spectra were measured by a Quanta Master 60 fluorimeter (Photon Technology International). The emission was collected under $90^{\circ}$ with respect to the excitation light. All emission spectra were corrected for the spectral sensitivity using the radiation of a tungsten lamp (Osram WI-14) The absorption and fluorescence measurements were performed in air equilibrated solutions at $293 \pm 2 \mathrm{~K}$ using standard rectangular cells $(1 \times 1 \mathrm{~cm}$, Hellma). Fluorescence quantum yields were determined using the standard sample method, using free base $5,10,15,20$-tetraphenylporphyrin as a standard $\left(\Phi_{\mathrm{ff}}^{0}=0.09\right.$ in air equilibrated toluene solution).$^{[30]}$ The sample concentrations were of the order of $1 \cdot 10^{-6} \mathrm{M}$ and were determined spectrophotometrically based on known extinction coefficients. All the samples were prepared by dissolving the porphyrin powder in dichloromethane, and the mono- and diprotonated forms were obtained by titration of the free base porphyrin solutions with perchloric acid $\left(\mathrm{HClO}_{4}\right)$.

\section{Results and Discussion}

\section{Ground state absorption spectra and conformational changes}

The ground state absorption spectra of $\mathbf{M e s}_{4}$ measured during the course of the acid-base titration are presented in Figure 1. Careful inspection of the spectral evolution upon going from the free base form to the diprotonated species indicates the absence of isosbestic points over the whole titration range. Such a picture is characteristic for situations where more than two species coexist. However, one can notice two sets of isosbestic points at the very beginning and very end of the titration procedure due to the separated equilibria free base - monoprotonated form and monoprotonated - diprotonated form. At the intermediate protonation steps, all three species coexist in solution and the porphyrin redistribution over these species is not accompanied by a retained set of isosbestic points. The plot of the absorbance at 437 versus $418 \mathrm{~nm}$, i.e. in the range of the Soret bands of the diprotonated and free base forms, has a clear concave shape (Figure 2), indicating the clearly different basicities 


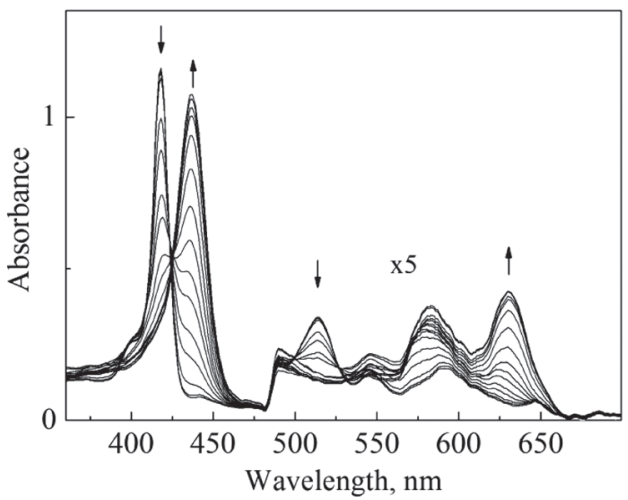

Figure 1. Ground state absorption spectra of $\mathbf{M e s}_{4}$ measured during the course of the titration. The arrows indicate the direction of the spectral changes upon going from the FB to the MP and DP forms.

of the free base and monoprotonated species. ${ }^{[47}$ and ref. 40 therein] in case of only two species in solution, the absorption band of the first species would grow at the expense of the second, resulting in a reciprocal dependence. This is the case for $\mathbf{P h} \mathbf{h}_{\mathbf{4}}$, where the protonation takes place as one single two-proton step (Figure 2).

The spectral changes for the $\mathbf{M e s}{ }_{3} \mathbf{P h}, \mathbf{M e s}_{2} \mathbf{P h} \mathbf{h}_{2}$-trans, $\mathbf{M e s}_{\mathbf{2}} \mathbf{P h} \mathbf{h}_{2}$-cis and $\mathbf{M e s} \mathbf{P h} \mathbf{h}_{3}$ porphyrin derivatives also reflect the equilibrium between the three species during the acidbase titration (see SI, Figure S1), thus providing unambiguous evidence for the formation of the monoprotonated form. in all these cases, the dominating bands in the absorption spectra are those belonging to the free base and diprotonated form, indicating the minor proportion of monoprotonated porphyrin. In case of $\mathbf{P} \mathbf{h}_{4}$, however, a single spectral evolution is observed over the whole titration range, with a clearly visible set of isobestic points, corresponding to the free base - diprotonated porphyrin transition (SI, Figure S1), in accordance with literature data. ${ }^{[10,19,32,36]}$

The data on the peak positions and intensity of all bands in the ground state absorption spectra of the free base

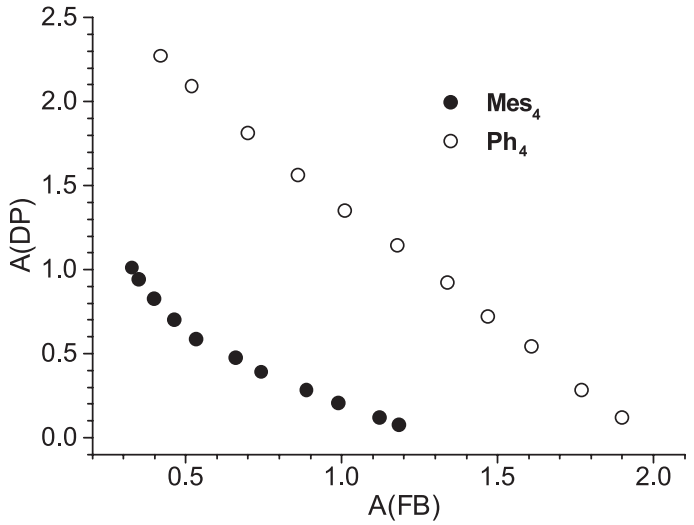

Figure 2. Relationship between the absorptivities measured at the maxima of the Soret bands for the FB and DP forms during the course of the titration for $\mathbf{M e s}_{4}(\bullet)$ and $\mathbf{P h}_{4}(\odot)$.

and diprotonated forms of all the studied porphyrins are summarized in Table 1.

One can see that the free base compounds are all practically indistinguishable with respect to their peak positions. Mes $_{4}$ has a bathochromic shift of $1 \mathrm{~nm}$ relative to all other compounds for the Soret band. However, when tracing the changes in the intensity of the $Q$ absorption bands, a clear evolution can be seen when going from $\mathbf{M e s}_{4}$ to $\mathbf{P h}_{4}$. Both $\mathbf{M e s}_{4}$ and $\mathbf{M e s}_{3} \mathbf{P h}$ reveal a "phyllo-type" spectrum, i.e. the intensity of the four $Q$ bands decreases in the order IV $>$ II $>$ III $>$ I. ${ }^{[48-49]}$ For $\mathbf{M e s}_{2} \mathbf{P h}_{2}-$ trans, the intensities of bands II and III are almost equal, and for the last three porphyrins, $\mathbf{M e s} \mathbf{P h}_{2}-\mathbf{c i s}, \mathbf{M e s} \mathbf{P h}$ and $\mathbf{P h}_{4}$, the $Q$ band intensities correspond to the "ethiotype", for which the band absorptivity decreases in the order IV $>$ III $>$ II $>I_{.}{ }^{[48,49]}$ Thus, for $\mathbf{M e s}_{4}$ and $\mathbf{M e s}_{3} \mathbf{P h}$ the intensities of the pure electronic transitions $Q_{x}(0,0)$ and $Q_{y}(0,0)$ (bands I and III) are low compared to their vibronic counterparts $Q_{x}(1,0)$ and $Q_{y}(1,0)$ (bands II and IV), and the relative intensities of the pure electronic transitions increase when more meso-mesityl groups are replaced with phenyl entities.

Table 1. Positions of the maxima and relative intensities (in parentheses) of the absorption bands in the UV-Vis spectra for the free base (FB) and diprotonated (DP) forms of all studied porphyrins.

\begin{tabular}{|c|c|c|c|c|c|c|c|c|}
\hline \multirow{2}{*}{ Porphyrin } & \multicolumn{5}{|c|}{ FB } & \multicolumn{3}{|c|}{ DP } \\
\hline & $\lambda_{\mathrm{I}}, \mathrm{nm}$ & $\lambda_{\mathrm{II}}, \mathrm{nm}$ & $\lambda_{\mathrm{III}}, \mathrm{nm}$ & $\lambda_{\mathrm{IV}}, \mathrm{nm}$ & $\lambda_{\text {Soret }}, \mathrm{nm}$ & $\lambda_{\mathrm{I}}, \mathrm{nm}$ & $\lambda_{\mathrm{II}}, \mathrm{nm}$ & $\lambda_{\text {Soret }}, \mathrm{nm}$ \\
\hline $\mathrm{Mes}_{4}$ & $\begin{array}{l}646.0 \\
(0.18)\end{array}$ & $\begin{array}{l}592.0 \\
(0.51)\end{array}$ & $\begin{array}{l}546.0 \\
(0.45)\end{array}$ & $\begin{array}{l}514.0 \\
(1.0)\end{array}$ & $\begin{array}{l}418.0 \\
(98.7)\end{array}$ & $\begin{array}{l}631.0 \\
(1.0)\end{array}$ & $\begin{array}{l}582.0 \\
(0.77)\end{array}$ & $\begin{array}{l}437.0 \\
(12.6)\end{array}$ \\
\hline $\mathbf{M e s}_{3} \mathbf{P h}$ & $\begin{array}{l}646.0 \\
(0.21)\end{array}$ & $\begin{array}{l}591.0 \\
(0.52)\end{array}$ & $\begin{array}{l}546.0 \\
(0.42)\end{array}$ & $\begin{array}{l}514.0 \\
(1.0)\end{array}$ & $\begin{array}{l}417.0 \\
(97.5)\end{array}$ & $\begin{array}{c}636.0 \\
(1.0)\end{array}$ & $\begin{array}{l}590.0 \\
(0.33)\end{array}$ & $\begin{array}{l}437.0 \\
(11.9)\end{array}$ \\
\hline $\mathbf{M e s}_{2} \mathbf{P h}_{2}$-trans & $\begin{array}{l}646.0 \\
(0.21)\end{array}$ & $\begin{array}{l}591.0 \\
(0.34)\end{array}$ & $\begin{array}{l}548.0 \\
(0.34)\end{array}$ & $\begin{array}{l}514.0 \\
(1.0)\end{array}$ & $\begin{array}{l}417.0 \\
(23.7)\end{array}$ & $\begin{array}{l}640.0 \\
(1.0)\end{array}$ & $\begin{array}{l}591.0 \\
(0.25)\end{array}$ & $\begin{array}{l}437.0 \\
(11.7)\end{array}$ \\
\hline Mes $_{2} \mathbf{P h}_{2}$-cis & $\begin{array}{l}646.0 \\
(0.22)\end{array}$ & $\begin{array}{l}591.0 \\
(0.32)\end{array}$ & $\begin{array}{l}548.0 \\
(0.34)\end{array}$ & $\begin{array}{c}514.0 \\
(1.0)\end{array}$ & $\begin{array}{l}417.0 \\
(24.3)\end{array}$ & $\begin{array}{c}643.0 \\
(1.0)\end{array}$ & $\begin{array}{l}591.0 \\
(0.28)\end{array}$ & $\begin{array}{l}438.0 \\
(10.5)\end{array}$ \\
\hline $\mathrm{Ph}_{3} \mathrm{Mes}$ & $\begin{array}{l}646.0 \\
(0.23)\end{array}$ & $\begin{array}{l}591.0 \\
(0.30)\end{array}$ & $\begin{array}{l}548.0 \\
(0.39)\end{array}$ & $\begin{array}{l}514.0 \\
(1.0)\end{array}$ & $\begin{array}{l}417.0 \\
(24.9)\end{array}$ & $\begin{array}{l}648.0 \\
(1.0)\end{array}$ & $\begin{array}{l}595.0 \\
(0.36)\end{array}$ & $\begin{array}{l}438.0 \\
(10.3)\end{array}$ \\
\hline $\mathbf{P h}_{4}$ & $\begin{array}{l}647.5 \\
(0.27)\end{array}$ & $\begin{array}{l}591.0 \\
(0.44)\end{array}$ & $\begin{array}{l}548.0 \\
(0.48)\end{array}$ & $\begin{array}{l}514.0 \\
(1.0)\end{array}$ & $\begin{array}{l}417.0 \\
(21.3)\end{array}$ & $\begin{array}{c}655.0 \\
(1.0)\end{array}$ & $\begin{array}{l}601.0 \\
(0.33)\end{array}$ & $\begin{array}{l}440.0 \\
(10.1)\end{array}$ \\
\hline
\end{tabular}


Such absorption spectral changes are related to the mutual position of the two highest occupied molecular orbitals (HOMO) of the porphyrin macrocycle. ${ }^{[49]}$ Using the orbital notation for the point symmetry group $D_{4 \mathrm{~h}}$, the minimum absorptivity is achieved when two HOMO $\mathrm{a}_{2 \mathrm{u}}$ and $\mathrm{a}_{1 \mathrm{u}}$ orbitals degenerate. The interaction of the two one-electron $\left(a_{1 u}, e_{g}\right)$ and $\left(a_{2 u}, e_{g}\right)$ configurations is maximal and the "intensity borrowing" from the highly allowed Soret transition decreases. When phenyl groups replace the mesityl groups at the meso-position(s), the spectral signature indicates that the $\mathrm{a}_{2 \mathrm{u}}$ orbital moves up (i.e. the phenyl groups are more electron donating compared with mesityl), thus decreasing the configuration interaction. As a result, the borrowed intensity from the Soret transition increases and the intensities of the pure electronic transitions $Q_{x}(0,0)$ and $Q_{y}(0,0)$ increase.

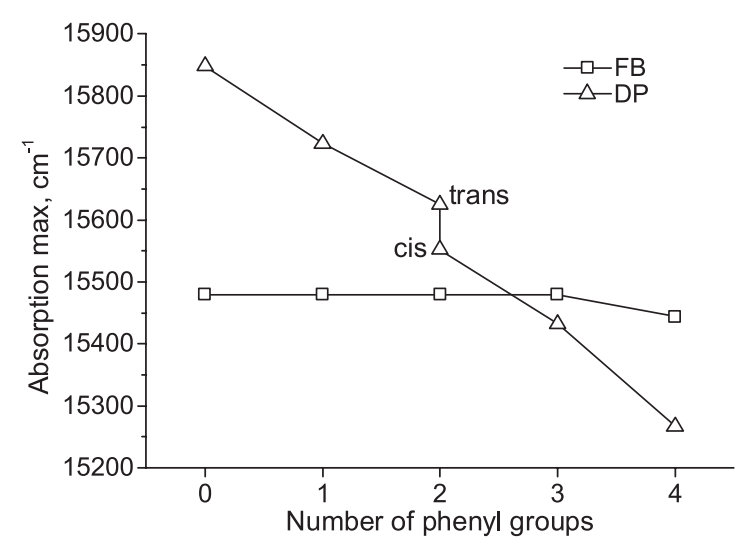

Figure 3. Absorption maximum as a function of the number of phenyl groups attached for the FB and DP forms.

The diprotonated forms of all studied porphyrins reveal a bathochromic shift of the long wavelength electronic transition upon progressive substitution of mesityl by phenyl groups. When going from $\mathbf{M e s}_{4}$ to $\mathbf{P h}_{4}$, the overall decrease in the 0-0 transition energy is $581 \mathrm{~cm}^{-1}$. Taking into account the absence of a spectral shift for the free bases, the electronic effects alone cannot explain such large spectral shifts. The main contribution seems to come from structural changes, namely the progressive increase in both the saddling and dihedral angles, as indicated above. ${ }^{[32,35,38]}$ However, the plot of the spectral shift as a function of the number of mesityl to phenyl groups exchanged reveals deviations from the simple additive dependence (Figure 3). The $\mathbf{M e s} \mathbf{P h}_{2}$-trans and $\mathbf{M e s} \mathbf{P h}_{2}$-cis derivatives carry the same substituents and hence have the same electronic effect from the meso-units on the $\pi$-system of the macrocycle (i.e. overall value of the electronic density they push in being the same), but the distribution of the mesityl and phenyl groups over the macrocycle is different. As a result, the $\mathbf{M e s} \mathbf{P h}_{\mathbf{2}}-$ trans porphyrin tends to retain a conformation closer to the one of the $\mathbf{M e s}_{4}$ porphyrin, whereas $\mathbf{M e s}_{2} \mathbf{P h}_{2}$-cis, being more flexible, seems to adopt a conformation closer to that of the $\mathbf{P} \mathbf{h}_{4}$ porphyrin. The energy difference $\Delta E_{\mathrm{Q}(0,0)}$ for the Mes, $\mathbf{P h} \mathbf{h}_{2}$-trans and Mes, $\mathbf{P h} \mathbf{h}_{2}$-cis derivatives is $73 \mathrm{~cm}^{-1}$, which can tentatively be related to the energy difference between these two macrocycle conformations. From the other side, the difference in flexibility of these two "Mes - -like" and "Ph $\mathbf{H}_{4}$-like" macrocycle conformations can be quantitatively estimated from the slope of the plot for the $\mathbf{M e s}_{4}$ to $\mathbf{M e s}_{2} \mathbf{P h} \mathbf{h}_{2}$ trans and $\mathbf{M e s} \mathbf{P h}_{2}$-cis to $\mathbf{P h} \mathbf{h}_{4}$ segments. Thus, these values are 112 and $143 \mathrm{~cm}^{-1}$. phenyl ${ }^{-1}$ (i.e. the shift in energy per phenyl attached) for the $\mathbf{M e s}$-like and $\mathbf{P h}_{4}$-like macrocycle conformations, respectively. Therefore, one can conclude that upon going from $\mathbf{M e s}_{4}$ to $\mathbf{P h}_{4}$, the macrocycle conformation changes through two modes: a) attachment of each sterically unhindered phenyl locally releases the macrocycle flexibility, allowing a (moderate) increase in the saddling angle $\varphi$ values of the adjacent pyrroles, i.e. "the additive mode"; b) attachment of two phenyls in adjacent meso-positions allows the interjacent pyrrole to adopt a maximum saddling angle $\varphi$ and extends the size of the flexible macrocycle domain, i.e. the "switch or flip mode".

\section{Fluorescence spectra and quantum yields}

The series of studied meso-tetraarylporphyrin compounds was found to show remarkable fluorescence properties in their lowest singlet excited $\mathrm{S}_{1}$ state. The free base derivatives of all six meso-tetraarylporphyrins are fluorescent, as are the mono- and diprotonated forms, except for $\mathbf{P h}_{\mathbf{4}}$. The latter, as stated above, does not stabilize the monoprotonated form in the ground state, and the lack of monoprotonated porphyrin fluorescence can be considered as an evidence for the absence of noticeable changes in the acid-base equilibrium in the excited $S_{1}$ state, which could result in the population of the excited state of the monoprotonated form of $\mathbf{P h}_{4}$. All the fluorescence spectra obtained during the course of the acid-base titrations are presented in Figure 4 (left). The separate sets of fluorescence spectra of the free base, mono- and diprotonated forms are also shown in Figure 4 (center).

The spectral profiles measured for all free base porphyrins were found to be very similar. The maximum position of the pure electronic $Q_{x}(0,0)$ band does not change within the experimental accuracy limits $( \pm 0.5 \mathrm{~nm})$ for all the five mesityl containing derivatives and undergoes a bathochromic shift of $2 \mathrm{~nm}$ for the $\mathbf{P h}_{4}$ porphyrin with respect to the above value (Table 2). The comparison of these values with those for the long wavelength electronic $Q_{x}(0,0)$ band in the absorption spectra indicates that the Stokes shift values $\left(\Delta \lambda_{\text {Stokes }}=\lambda_{\text {abs }}-\lambda_{\mathrm{ff}}\right)$ are practically not affected by mesityl to phenyl substitution. The Stokes shift is known to be a marker for the degree of the structural changes occurring between the ground $\left(\mathrm{S}_{0}\right)$ and excited $\mathrm{S}_{1}$ states of porphyrins. ${ }^{[33]}$ Therefore, one can expect that the molecular conformation of every compound in its excited singlet $\mathrm{S}_{1}$ state does not change noticeably as compared to that in the electronic ground state.

On the contrary, the spectra of the diprotonated forms undergo a progressive bathochromic shift and a decrease in the relative intensity of the vibronic $Q_{x}(0,1)$ band with respect to that of the electronic $Q_{x}(0,0)$ band upon mesityl to phenyl substitution (Figure 4, Table 1). The trends of the spectral shift direction for both the absorption and fluorescence of the diprotonated forms are hence the same. However, there are some functional differences (Figure 5). Thus, the fluorescence $Q_{x}(0,0)$ band maximum decreases linearly with an increase in the number of sterically unhindered substitu- 

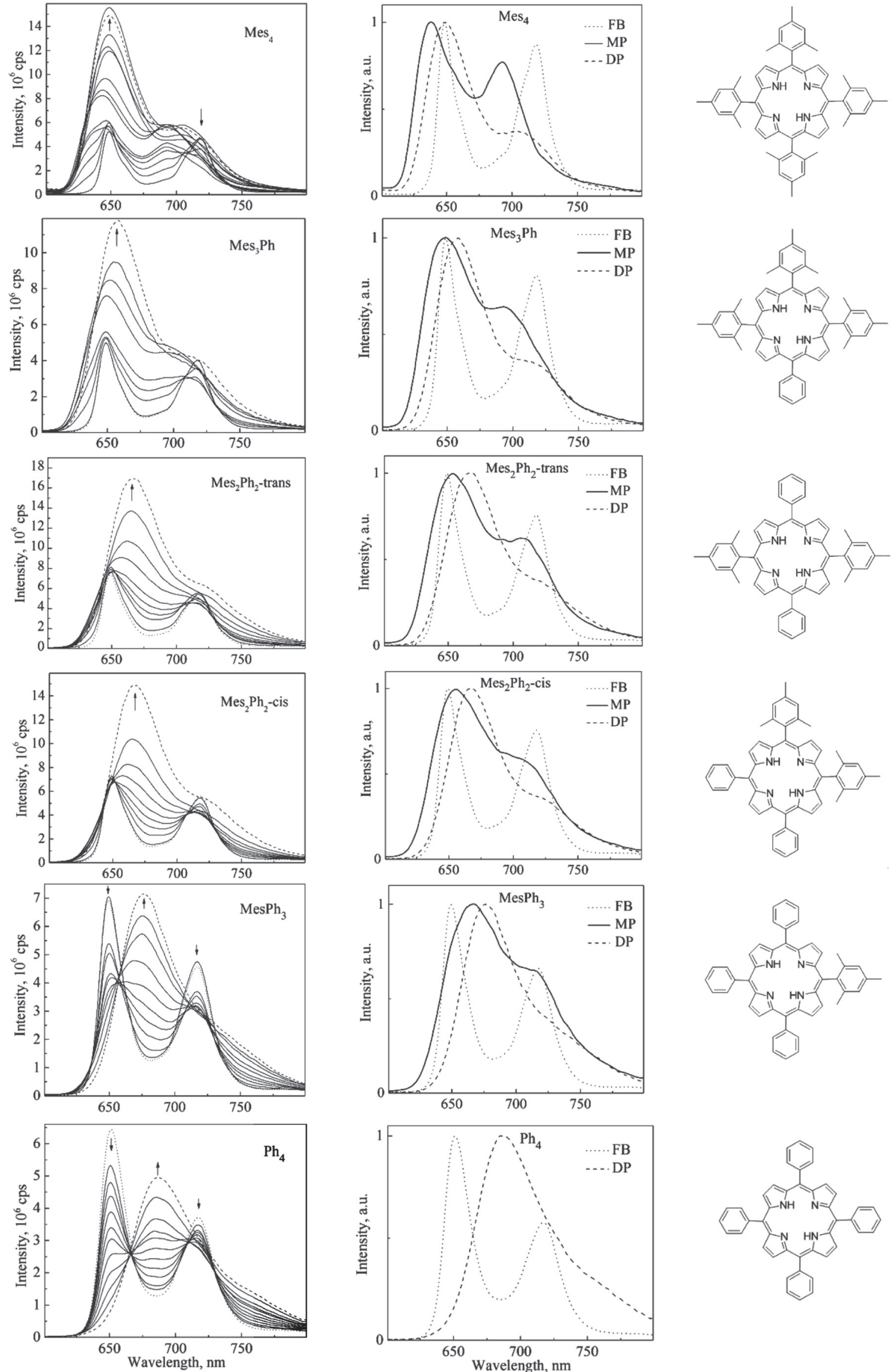

Figure 4. Absorbance-normalized fluorescence spectra measured during the course of the titration (left), individual (normalized on the peak intensity) fluorescence spectra of the FB, MP and DP forms (center), and molecular structures of the corresponding tetraarylporphyrins (right). 
Table 2. Positions of the maxima in the fluorescence spectra and the fluorescence quantum yields for all studied compounds in their free base (FB), monoprotonated (MP) and diprotonated (DP) form.

\begin{tabular}{|c|c|c|c|c|}
\hline \multirow{2}{*}{ Porphyrin } & \multirow{2}{*}{ Form } & \multicolumn{2}{|c|}{$\lambda_{\mathrm{fl}}^{\max }, \mathrm{nm}$} & \multirow{2}{*}{$\Phi_{\mathrm{fl}} \times 10$} \\
\hline & & $\mathrm{Q}_{\mathrm{x}}(0,0)$ & $\mathrm{Q}_{\mathrm{x}}(1,0)$ & \\
\hline \multirow{3}{*}{$\mathrm{Mes}_{4}$} & FB & 649.0 & 717.0 & 8.3 \\
\hline & MP & 638.0 & 693.0 & 20.8 \\
\hline & DP & 649.0 & 705.0 & 30.0 \\
\hline \multirow{3}{*}{$\mathrm{Mes}_{3} \mathrm{Ph}$} & FB & 649.0 & 717.0 & 7.1 \\
\hline & MP & 647.0 & 694.0 & 13.0 \\
\hline & DP & 657.0 & 715.0 & 21.5 \\
\hline \multirow{3}{*}{$\operatorname{Mes}_{2} \mathbf{P h}_{2}$-trans } & FB & 649.0 & 717.0 & 6.6 \\
\hline & MP & 653.0 & $\sim 710.0$ & 13.5 \\
\hline & DP & 667.0 & $\sim 720.0$ & 21.0 \\
\hline \multirow{3}{*}{$\operatorname{Mes}_{2} \mathbf{P h}_{2}-c i s$} & FB & 649.0 & 717.0 & 6.6 \\
\hline & MP & 656.0 & $\sim 710.0$ & 10.0 \\
\hline & DP & 667.0 & $\sim 725.0$ & 17.6 \\
\hline \multirow{3}{*}{$\mathrm{MesPh}_{3}$} & FB & 649.0 & 717.0 & 7.0 \\
\hline & MP & 666.0 & $\sim 715.0$ & 6.0 \\
\hline & DP & 676.0 & $\sim 740.0$ & 10.2 \\
\hline \multirow{3}{*}{$\mathbf{P h}_{4}$} & FB & 651.0 & 717.0 & 9.0 \\
\hline & MP & - & - & - \\
\hline & DP & 687.0 & $\sim 750.0$ & 10.5 \\
\hline
\end{tabular}

ents (with a plot slope of $213 \mathrm{~cm}^{-1}$ phenyl ${ }^{-1}$ ) for the diprotonated porphyrins. As a result, the Stokes shift value increases upon going from Mes $\mathbf{M}_{4}$ to $\mathbf{P h}$ for about $270 \mathrm{~cm}^{-1}$ (Figure 6).

The substantially larger $\Delta \lambda_{\text {Stokes }}$ values in case of the diprotonated porphyrins as compared to the free bases indicate a larger magnitude of structural rearrangements in the excited $\mathrm{S}_{1}$ state for the former. Moreover, these structural rearrangements are unequal, being larger for the phenyl-rich derivatives. The increase in porphyrin macrocycle flexibility with a decrease in steric hindrance imposed by the ortho- $\mathrm{CH}_{3}$ groups allows an enhanced structural relaxation in the excited $\mathrm{S}_{1}$ state. The Stokes shift dependence hence reflects the same switching of the molecular conformation as revealed above for the absorption maximum dependence (Figure 3) with an energy difference

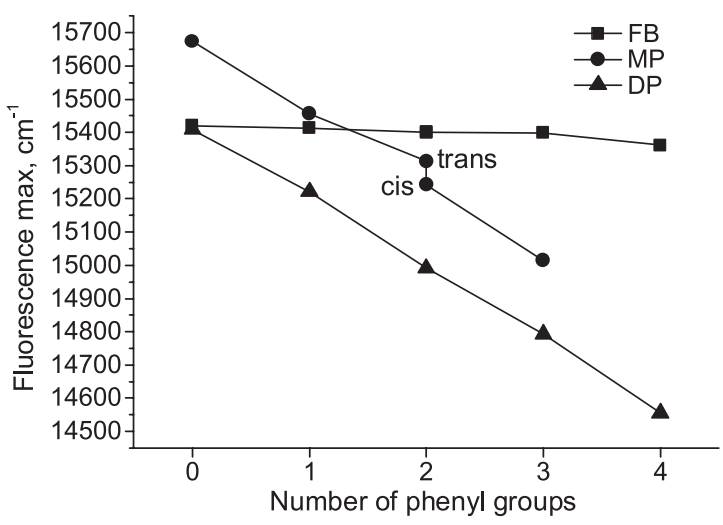

Figure 5. Fluorescence maximum as a function of the number of phenyl groups attached for the FB, MP and DP forms.

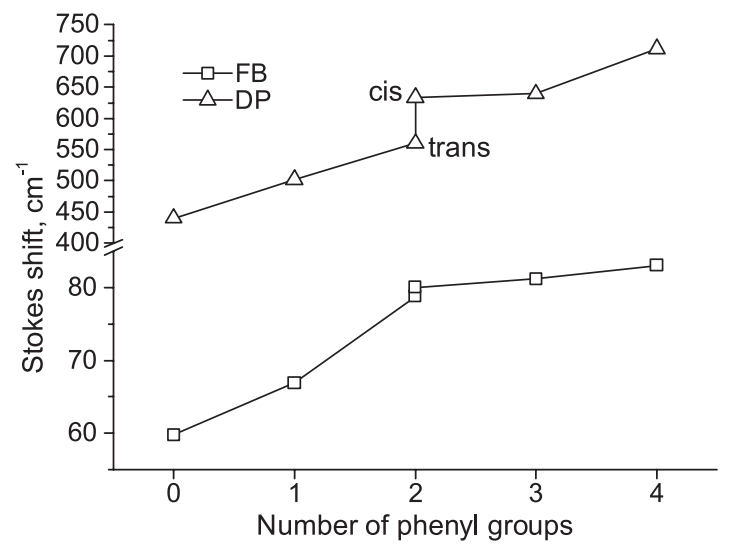

Figure 6. Stokes shift as a function of the number of phenyl groups attached for the FB and DP forms.

$\Delta E_{\mathrm{Q}(0,0)}$ for the $\mathbf{M e s} \mathbf{P h}_{2}$-trans and $\mathbf{M e s}_{\mathbf{2}} \mathbf{P} \mathbf{h}_{\mathbf{2}}$-cis derivatives of $73 \mathrm{~cm}^{-1}$. At the same time, one needs to state that the structural differences of the diprotonated forms of $\mathbf{M e s} \mathbf{P h}_{2}$-cis, $\mathbf{M e s} \mathbf{P h}_{3}$ and $\mathbf{P h}_{4}$ in the excited $\mathrm{S}_{1}$ state are smaller compared to those in the electronic ground state. The opposite is valid for the diprotonated forms of $\mathbf{M e s} \mathbf{P h}_{2}$-trans, $\mathbf{M e s}{ }_{3} \mathbf{P h}$ and $\mathbf{M e s}_{4}$. This expectation derives from the comparison of the Stokes shift plot slopes for the $\mathbf{M e s}_{4}$ to $\mathbf{M e s}_{2} \mathbf{P h}_{2}$-trans and $\mathbf{M e s} \mathbf{P h}_{2}-$ cis to $\mathbf{P h}_{4}$ transitions, which were found to be 120 and $78 \mathrm{~cm}^{-1}$ phenyl ${ }^{-1}$.

The progressive changes in the relative intensities of the $Q_{x}(0,1)$ and $Q_{x}(0,0)$ bands reflect the increased degree of nonplanar saddle type distortion of the macrocycle. It is accepted nowadays that vibronic transitions of porphyrin fluorescence spectra may appear due to so-called intensity borrowing from the intense electronic transitions by the Hertzberg-Teller mechanism. Accordingly, intensity borrowing is possible when the direction of the vibration and the transition dipole moment orientations are the same (i.e. the cosine of the angle between them is nonzero). Thus, the out-of-plane vibrations, which have frequencies not higher than $1000 \mathrm{~cm}^{-1}$, enhance when the molecule is nonplanar and the transition dipole moment has a component orthogonal to the molecular plane (Z-component). ${ }^{[50]}$ The increase in the degree of saddle type distortion upon going from the $\mathbf{M e s}_{4}$ to $\mathbf{P h}_{4}$ porphyrin (the saddling angles $\varphi$ are about 15 and $21-30^{\circ}$, respectively $)^{[32,38]}$ facilitates the intensity borrowing. As a result, the fluorescence intensity in the range between the $Q_{x}(0,1)$ and $Q_{x}(0,0)$ bands $(i . e$. that corresponding to the out of plane vibrations) increases, leading to asymmetry of the main fluorescence band and increase of its halfwidth. The observed change in the relative intensities of the $Q_{x}(0,1)$ and $Q_{x}(0,0)$ bands is an accompanying feature.

The evolution of the spectral features for the fluorescence spectra of the free bases and diprotonated forms can be evaluated rather easily, since these spectra are measured directly at the beginning and the end of the titration procedure. Unfortunately, the analysis of the monoprotonated species fluorescence cannot be undertaken in the same manner, since the fluorescence spectra of the monoprotonated forms for all derivatives are superimposed on those of the free bases and diprotonated forms. This is due to the close 
values of the basicity constants of the two acid-base equilibria involved. Inspection of the spectral evolution during the course of the titration unambiguously reveals the presence of the fluorescence from the monoprotonated form, as evidenced by a) the absence of isosbestic points in the spectra during the titration; b) the opposite directions of the spectral shifts at the beginning (the hypsochromic shift when the free base - monoprotonated form transition dominates) and at the end (the bathochromic shift when the monoprotonated - diprotonated form transition dominates) of the titration procedure. Thus, to characterize the fluorescence of the monoprotonated form, we have carried out a spectral deconvolution and the fluorescence spectra of the monoprotonated form shown (Figure 4, center) were evaluated with such a procedure. The principle was the same as applied recently to the evaluation of the individual fluorescence spectra of corrole NH tautomers. ${ }^{[51]}$ The only difference here is that we have analyzed the spectra at different acid concentrations at the very beginning and very end of the titration, where only two emissive species are expected to coexist (rather than at different temperatures as it was in the former case). Additionally, when available, the validity of the evaluation of the spectral profiles was verified by the determination of the hidden bands maxima with the second derivative method. ${ }^{[52]}$

The fluorescence spectra of the monoprotonated form also demonstrate a bathochromic shift of the band maxima upon going from $\mathbf{M e s}$ to $\mathbf{P h}_{4}$. However, if the $Q_{x}(0,1)$ band peak position of the monoprotonated species is compared with the corresponding value for the free base, one can see that the spectra of the monoprotonated form of $\mathbf{M e s}_{\mathbf{4}}$ and $\mathbf{M e s}_{\mathbf{3}} \mathbf{P h}$ show hypsochromic shifts, whereas for the other three derivatives $\left(\mathbf{M e s}_{2} \mathbf{P h} \mathbf{h}_{2}\right.$-trans, $\mathbf{M e s}_{2} \mathbf{P h} \mathbf{h}_{\mathbf{2}}$-cis and $\mathbf{M e s}_{\mathbf{P h}}$ ) a bathochromic shift is observed. On the other hand, all monoprotonated porphyrin spectra show hypsochromic shifts as compared to their diprotonated counterparts. a progressive increase in the band halfwidth upon increasing the number of sterically unhindered meso-substituents is also observed, which can be considered as a manifestation of the out of plane vibrations in the fluorescence spectra of the monodeprotonated form. The spectrum of monoprotonated $\mathbf{M e s} \mathbf{P h}_{\mathbf{3}}$ is approaching that of diprotonated $\mathbf{P h} \mathbf{h}_{\mathbf{4}}$ (both with respect to spectral shape and position). This trend allows suggesting that the molecular conformations of these compounds are very similar, such that the attachment of the proton needs minimal additional structural accommodation. This observation is in line with the conclusion made previously that $\mathbf{P h}_{\mathbf{4}}$ adopts a conformation with high saddling angle upon attachment of the first proton. The degree of distortion for this conformation (saddling angle $\varphi$ ) was found to be almost the same as was determined for the diprotonated form of $\mathrm{Mes}_{4} \cdot{ }^{[38]}$

In contrast to the cases for the free base and diprotonated forms, there is a signature switch for the dependence of the $Q_{x}(0,1)$ band peak position on the number of unhindered meso-aryl substituents (Figure 5), i.e. there is non-additivity in the substitution dependent structural rearrangement in the excited $\mathrm{S}_{1}$ state. An energy value of $71 \mathrm{~cm}^{-1}$ can be related to these conformational changes. This value is of the same order of magnitude as that corresponding to the ground state structural rearrangement in the diprotonated species. The plot slopes for the $\mathbf{M e s}{ }_{4}$ to $\mathbf{M e s} \mathbf{P h}_{2}$-trans and $\mathbf{M e s} \mathbf{P h}_{\mathbf{2}}$-cis to $\mathbf{M e s} \mathbf{P h}_{3}$ transitions are 180 and $213 \mathrm{~cm}^{-1}$. phenyl $\mathrm{l}^{-1}$, respectively. Comparison of these last values with those determined for the diprotonated forms allows suggesting that the molecular conformations of the monoprotonated forms of $\mathbf{M e s} \mathbf{P h}_{2}$-cis and $\mathbf{M e s} \mathbf{P h}_{3}$ have flexibilities close to their diprotonated forms.

The absorbance normalized fluorescence spectra show an increase in the integral intensity for all the studied compounds upon formation of the protonated products (Figure 4, left). This implies that the fluorescence quantum yields increase for all the protonated forms. Direct measurements of the fluorescence quantum yields were applied to the free bases and diprotonated forms of all studied porphyrins. The fluorescence quantum yields of the monoprotonated forms were determined with an indirect procedure developed earlier for the intermediate protonation species. ${ }^{[47]}$ All $\Phi_{\mathrm{fl}}$ values are summarized in Table 2 . The obtained $\Phi_{\mathrm{fl}}$ values are also plotted as a function of the number of attached unhindered meso-aryl substituents (Figure 7).

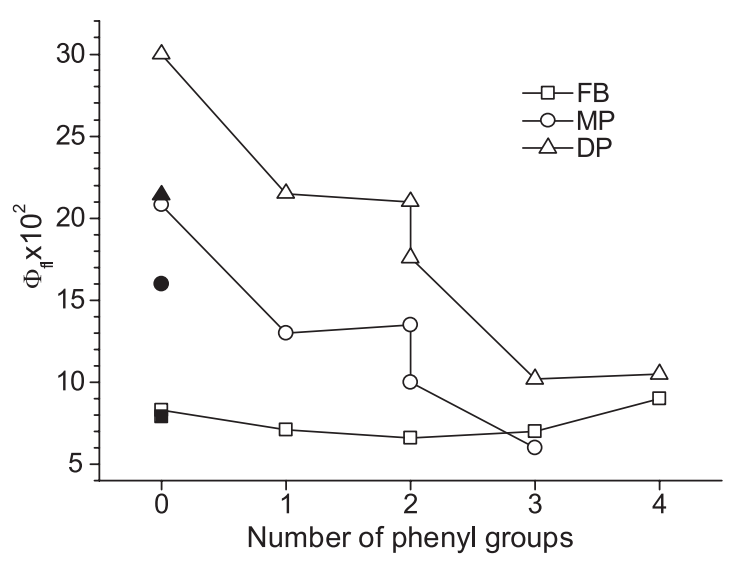

Figure 7. Fluorescence quantum yield as a function of the number of phenyl groups attached for the FB, MP and DP forms. The closed symbols indicate the corresponding data for the three species of $\mathbf{M e s}_{4}$ measured in THF-TFA solutions. ${ }^{[28]}$

The fluorescence quantum yields change due to the attachment of additional protons in the macrocyclic core, the formation of the saddle type macrocycle conformation, which is expected to show an enhanced rate of radiationless deactivation of the excited $\mathrm{S}_{1}$ state, and the possibility of fluorescence quenching upon association of positively charged macrocyclic core and negatively charged acid residues. ${ }^{[10,34,36,37,53]}$ in the case under consideration, the fluorescence quantum yields increase, indicating that quenching by the perchlorate counter ions is negligibly small (if any). Moreover, the anion binding constant should vary only slightly for structurally similar compounds, so the quenching effects (if they take place) would be of the same order of magnitude for all six porphyrin derivatives. Therefore, the saddling distortion of the porphyrin macrocycle needs to be analyzed to explain the observed trends in $\Phi_{\mathrm{fl}}$. We have shown earlier that the attachment of protons to the porphyrin core is accompanied with an increase of the fluorescence probability $k_{\mathrm{fl}}$ (radiative deactivation rate). ${ }^{[36]}$ From the other side, the formation of a highly distorted conformation leads to an enhancement of the radiationless $\mathrm{S}_{1} \rightarrow \mathrm{S}_{0}$ internal conver- 
sion rate $k_{\mathrm{IC}}{ }^{[33,36]}$ Thus, the $\Phi_{\mathrm{fl}}$ value results from competition between these two probabilities and is function of the molecular flexibility of the porphyrin. in our previous paper, we demonstrated that in symmetrical meso-tetraaryl substituted porphyrin derivatives with bulky methyl groups in the ortho, ortho'-positions of the aryl rings, $\Phi_{\mathrm{fl}}$ shows an almost linear growth for each protonation step. ${ }^{[36]}$ We have ascribed this behaviour to the rigidity of the macrocycle due to steric hindrance. There was no possibility to access the conformer having an enhanced radiationless $\mathrm{S}_{1} \rightarrow \mathrm{S}_{0}$ internal conversion rate. As a result, the only remaining factor contributing to the $\Phi_{\mathrm{fl}}$ value is protonation, which leads to an increase in the emission probability.

Thus, the differences in the fluorescence quantum yields for both the mono- and diprotonated forms of the studied compounds must be related to the differences in their molecular flexibility. An increase in $\Phi_{\mathrm{fl}}$ is observed for all compounds, but its magnitude differs significantly. in case of $\mathbf{P h}_{4}$, whose peripheral substitution pattern facilitates stabilization of the highly distorted macrocycle, the increase in $\Phi_{\mathrm{f}}$ for the diprotonated form with respect to the free base barely exceeds the experimental accuracy limits (0.105 vs. 0.09; Table 2). The least distorted $\mathbf{M e s}_{4}$ porphyrin demonstrates an enhancement of more than a factor of three, resulting in a $\Phi_{\mathrm{fl}}$ value of 0.30 for the diprotonated species. It needs to be mentioned here that these values and the $\Phi_{\mathrm{fl}}$ values for the mono- and diprotonated forms of $\mathbf{M e s}_{4}$ reported earlier $^{[36]}$ do not contradict one another. The difference in these two sets of $\Phi_{\mathrm{fl}}$ values (see Figure 7) can be assigned to the use of two different acids, i.e. trifluoroacetic acid in the former case and perchloric acid here, which differ in association constants of the conjugate anions. As a result, fluorescence quenching by the two attached trifluoroacetate anions takes place, whereas the perchlorate ions are loosely bound to the protonated porphyrin species. This dependence of the fluorescence quantum yield on the type of acid used in the titration experiments (especially in low polar and, consequently, weakly solvating solvents) is well documented. ${ }^{[37]}$

The relationships between the macrocycle flexibility and $\Phi_{\mathrm{fl}}$ for the free bases, mono- and diprotonated forms reflect both the additive and switching effects (Figure 7). Thus, for the free bases of $\mathbf{M e s}_{4}, \mathbf{M e s}_{3} \mathbf{P h}$ and $\mathbf{M e s} \mathbf{P h}_{2}$-trans, the $\Phi_{\mathrm{fl}}$ value decreases with an increase in the number of sterically unhindered aryls. The $\Phi_{\mathrm{ff}}$ values for $\mathbf{M e s} \mathbf{P h}_{\mathbf{2}} \mathbf{P}$-trans and $\mathbf{M e s} \mathbf{P h}_{2}$-cis were found to be the same, and the further increase in the number of phenyl groups results in further $\Phi_{\mathrm{fl}}$ enhancement. The turnover of the dependence occurs for the $\mathbf{M e s}_{2} \mathbf{P h} \mathbf{h}_{2}$ derivatives. For both sets of mono- and diprotonated molecules, the structural changes when going from the less flexible $\mathbf{M e s} \mathbf{P h}_{\mathbf{2}}$-trans to the more flexible $\mathbf{M e s} \mathbf{P h}_{\mathbf{2}}$-cis account for the sharp change of the fluorescence properties.

\section{Spectra-structure correlations and configuration interaction}

The interpretation of the origin of the changes in the spectral and fluorescence properties is a complex problem, as three effects are superimposed: a) the substantial saddle type nonplanar distortion of the porphyrin macrocycle induced by the attachment of (a) proton(s); b) the conjugation of the aromatic peripheral meso-substitu- ents with the conjugated $\pi$-electron system of the porphyrin macrocycle; c) the electronic density redistribution between the macrocycle and periphery by means of inductive and mesomeric effects. An attempt of theoretical consideration of any of the above effects alone would suffer from undesired interference with the two other factors. Nonetheless, some particular features of the spectral behavior of the studied mixed mesityl-phenyl porphyrins can be derived from the results presented above.

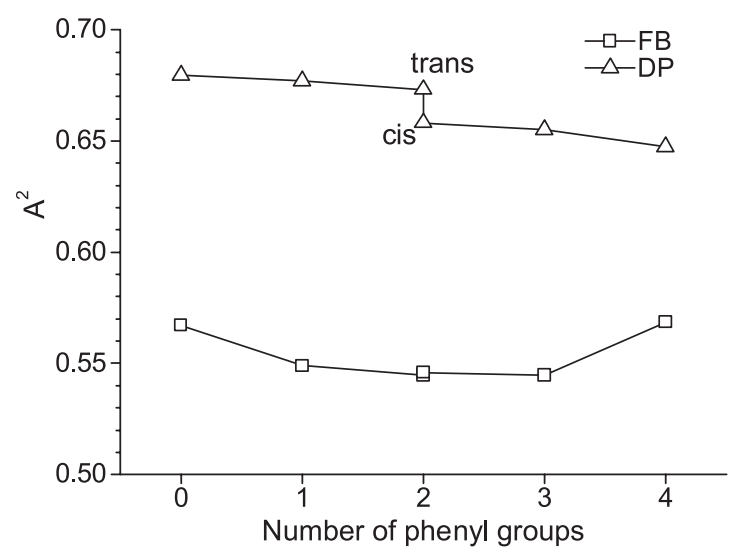

Figure 8. Weight $\mathrm{A}^{2}$ of the one electron $\left(\mathrm{a}_{2 \mathrm{u}}, \mathrm{e}_{\mathrm{g}}\right)$ configuration as a function of the number of phenyl groups attached for the FB and DP forms.

The saddle type macrocycle distortion seems to be the main factor to account for the spectral shifts upon mesityl to phenyl substitution at the meso-positions. Saddling angles $\varphi$ of 15 and $21^{\circ}$, and dihedral angles $\theta$ of 71 and $45^{\circ}$, have been calculated for the diprotonated forms of $\mathbf{M e s}_{4}$ and $\mathbf{P h}_{4}$, respectively. ${ }^{[38]}$ The $Q_{x}(0,0)$ band energy difference between the two conformers of diprotonated $\mathbf{P h}_{4}$ with the same sets of saddling and dihedral angles was calculated to be about $550 \mathrm{~cm}^{-1} .^{[54]}$ The experimental difference for the diprotonated forms of $\mathbf{M e s}_{4}$ and $\mathbf{P h}_{4}$ is $581 \mathrm{~cm}^{-1}$. Here, the changes in the dihedral angle, which ultimately accompany the pyrrole tilting and modulate the degree of $\pi$-electron orbital overlap, are already taken into account. Moreover, the quantum-chemical data used for the above estimations have been obtained with untruncated molecular structures, which, as it was shown before, ${ }^{[55]}$ provide the best correlation with experiments. Thus, the saddling induced spectral shifts are able to account for most of spectral shift observed. The difference in saddling angle is due to the two ortho,ortho'-methyl groups attached to the aryl ring. Alkyl groups are known to be electron donating substituents, but, depending on their position on the aryl ring, electronic communication could have opposite signs. ${ }^{[19]}$ Indeed, ortho- $\mathrm{CH}_{3}$ and para- $-\mathrm{CH}_{3}-$ substituted tetraphenylporphyrins reveal small hypsochromic $(2.1 \mathrm{~nm})$ and bathochromic $(2.3 \mathrm{~nm})$ shifts with respect to the unsubstituted tetraphenylporphyrin, respectively, and the same trend was shown to be retained for their diprotonated forms. ${ }^{[19]}$ For the mesityl substituents, both the ortho$\mathrm{CH}_{3}$ and para- $\mathrm{CH}_{3}$ effects seem to disappear due to destructive interference, as described above, and as a result the free base ground state absorption spectra of the studied compounds remain unchanged compared to that of $\mathbf{P h} \mathbf{h}_{\mathbf{4}}$ (Table 1). 
Therefore, this effect can also be excluded from the consideration in the case of protonated species.

The phyllo-ethio transition in the $Q$-bands spectral profile upon going from $\mathbf{M e s}{ }_{4}$ to $\mathbf{P h}_{4}$ (vide supra) relates to the mutual position of the two highest occupied molecular orbitals (HOMO and HOMO-1) of the porphyrin macrocycle. The monotonic increase of the electronic to vibronic intensity $Q(0,0) / Q(1,0)$ ratio upon going from $\mathbf{M e s}$ to $\mathbf{P h}$ indicates that the $\mathrm{a}_{2 \mathrm{u}}$-like orbital is the HOMO and the $\mathrm{a}_{1 \mathrm{u}}$-like orbital is the HOMO-1. Direct correlation between the spectral shifts and the positioning of the two HOMO $\mathrm{a}_{2 \mathrm{u}}$ and $\mathrm{a}_{1 \mathrm{u}}$ orbitals has no sense since the structural changes superimpose. However, the one-electron configuration weights can be estimated within the framework of the four orbital Gouterman model based on the relative absorptivity of the visible and Soret bands. ${ }^{[49,56,57]}$ In case of the free base porphyrins, the squared weight $\mathrm{A}^{2}$ of the one-electron $\left(\mathrm{a}_{2 \mathrm{u}}, \mathrm{e}_{\mathrm{g}}\right)$ configurations for both $\mathbf{M e s}_{4}$ and $\mathbf{P h}$ was found to be 0.57 , and in all asymmetrical derivatives this value is about 0.55 (the squared weight $\mathrm{B}^{2}$ of the one-electron $\left(\mathrm{a}_{1 \mathrm{u}}, \mathrm{e}_{\mathrm{g}}\right)$ configuration can be found from the normalization relationship $\mathrm{A}^{2}+\mathrm{B}^{2}=1$ ). For the diprotonated porphyrins, the $A^{2}$ value for the one-electron $\left(a_{2 u}, e_{g}\right)$ configuration lies in the range $0.645-0.680$, indicating an increase in the energy gap between the $\mathrm{a}_{2 \mathrm{u}}$ and $\mathrm{a}_{1 \mathrm{u}}$ molecular orbitals. It is of interest to trace the value of $\mathrm{A}^{2}$ for the oneelectron $\left(a_{2 u}, e_{g}\right)$ configuration as a function of the number of phenyl moieties attached (Figure 8). This plot clearly demonstrates that the configuration interaction changes in the switch mode at the $\mathbf{M e s} \mathbf{P h}_{\mathbf{2}}$-trans to $\mathbf{M e s} \mathbf{P h}_{\mathbf{2}}$-cis transition, along with slight additive changes in the ranges before and afterwards.

\section{Conclusions}

The molecular conformations and spectral-luminescent properties of meso-tetraaryl substituted porphyrins depend on the difference in the rotational degree of freedom of the meso-aryl groups and the porphyrin substitution pattern. An additive pattern following sterically hindered to unhindered aryl group substitution was found for all studied porphyrins. For both the mono- and diprotonated species, two molecular conformations were revealed, a first one for $\mathbf{M e s}_{4}, \mathbf{M e s} 3 \mathbf{P h}$ and $\mathbf{M e s} \mathbf{P h}_{2}$-trans, and a second one for $\mathbf{M e s} \mathbf{P h}_{2}$-cis, $\mathbf{M e s} \mathbf{P h}_{3}$ and $\mathbf{P h}_{\mathbf{4}}$. Within both of these subgroups, the spectral changes follow an additive mode, whereas the structural transition from $\mathbf{M e s} \mathbf{P h}_{2}$-trans to $\mathbf{M e s} \mathbf{P h}_{2}$-cis promotes a switch mode. The fluorescence spectra and fluorescence quantum yields of all mono- and diprotonated species are reported and the relationship with the molecular structure of the compounds was analyzed in detail. The reported results are of particular importance for the interpretation (prediction) of the optical features of dendritic structures with a porphyrin core, ${ }^{[58-61]}$ especially with respect to the acid-base equlibria in the porphyrin macrocycle core.

Acknowledgements. This work was supported by an FP-7 grant from the EC for Research, Technological Development and Demonstration Activities, "Dendrimers for Photonic Devices" (IRSES-PEOPLE-2009-247260-DphotoD), under the "International Research Staff Exchange Scheme". The authors acknowledge the FWO (WOG "Supramolecular Chemistry and Materials") and BELSPO (IAP 7/05 "Functional Supramolecular Systems") for financial support. M. Kruk acknowledges the State Program of Scientific Researches of the Republic of Belarus "Convergence-2020" for the financial support. T. Ngo thanks ICYS (the International Center for Young Scientists) for continuing support and the Alexander von Humboldt Foundation for a post-doctoral fellowship.

\section{References}

1. Smith K.M. In: The Porphyrin Handbook, Vol. 1 (Kadish K.M., Smith K.M., Guillard R., Eds.), San Diego: World Scientific, 2000.

2. Milgrom L.R. The Colours of Life: An Introduction to the Chemistry of Porphyrins and Related Compounds, Oxford: Oxford University Press, 1997. 249 p.

3. Li L.L., Diau E.W.G. Chem. Soc. Rev. 2013, 42, 291-304.

4. Kesters J., Verstappen P., Kelchtermans M., Lutsen L., Vanderzande D., Maes W. Adv. Energy Mater. 2015, 1500218.

5. Bonnett R. Chemical Aspects of Photodynamic Therapy. Amsterdam: Gordon and Breach Science Publishers, 2000. 305 p.

6. Hecht S., Fréchet J.M.J. Angew. Chem. Int. Ed. 2001, 40, 75-91.

7. Lindsey J.S. meso-Tetraarylporphyrin Derivatives: New Synthetic Methodologies. In: The Porphyrin Handbook, Vol. 2 (Kadish K.M., Smith K.M., Guillard R., Eds.), San Diego: World Scientific, 2000. p. 45-118.

8. Adler A.D., Longo F.R., Finarelli J.D., Goldmacher J., Assour J., Korsakoff L. J. Org. Chem. 1967, 325, 476.

9. Shanmugathasan S., Edwards C., Boyle R.W. Tetrahedron 2000, 56, 1025-1046.

10. Stone A., Fleischer E.B. J. Am. Chem. Soc. 1968, 90, 27352748.

11. Kobuke Y., Miyagi H. J. Am. Chem. Soc. 1994, 116, 41114112.

12. Bruix M., Elguero J., Meutermans W. J. Chem. Res. (S) 1992, 370-371.

13. Furuta H., Maeda H., Furuta T., Osuka A. Org. Lett. 2000, 2, 187-189.

14. Gupta I., Hung C.-H., Ravikanth M. Eur. J. Org. Chem. 2003, 4392-4400.

15. Bruekner C., Foss P.C.D., Sullivan J.O., Pelto R., Zeller M., Birge R.R., Crundwell G. Phys. Chem. Chem. Phys. 2006, 8 , 2402-2412.

16. Lee W.A., Gratzel M., Kalynasundaram K. Chem. Phys. Lett. 1984, 107, 308-313.

17. Hambright P., Gore T., Burton M. Inorg. Chem. 1976, 15, 2314-2315.

18. Thomas D.W., Martell A.E. J. Am. Chem. Soc. 1956, 78, 13351338.

19. Meot-Ner M., Adler A.D. J. Am. Chem. Soc. 1975, 97, 51075111.

20. Freitag R.A., Whitten D.G. J. Phys. Chem. 1983, 87, 39183925.

21. Wolberg A. J. Mol. Struct. 1974, 21, 61-66.

22. Eaton S.S., Eaton G.R. J. Am. Chem. Soc. 1975, 97, 36603666.

23. Quimby D.J., Longo F.R. J. Am. Chem. Soc. 1975, 97, 51115117.

24. Egorova G.D., Knyukshto V.N., Solovyov K.N., Tsvirko M.P. Opt. Spectrosk. [Opt. Spectrosc.] 1980, 48, 1101-1107 (in Russ.).

25. Kalyanasundaram K. J. Phys. Chem. 1984, 23, 2453-2459.

26. Sutter T.P.J., Rahimi R., Hambright P., Bommer J.C., Kumar M., Neta P. J. Chem. Soc. Faraday Trans. 1993, 89, 495-502. 
27. Fonda H.N., Gilbert J.V., Cormier R.A., Sprague J.R., Kamioka K., Connoly J.S. J. Phys. Chem. 1993, 97, 7024-7033.

28. Knyukshto V.N., Solovyov K.N., Mironov A.F., Egorova G.D., Efimov A.V. Opt. Spectrosk. [Opt. Spectrosc.] 1998, 85, 592600 (in Russ.).

29. Knyukshto V., Zenkevich E., Sagun E., Shulga A., Bachilo S. Chem. Phys. Lett. 1998, 297, 97-108.

30. Knyukshto V.N., Solovyov K.N., Egorova G.D. Biospectroscopy 1998, 4, 121-133.

31. Senge M.O. J. Photochem. Photobiol. B: Biol. 1992, 16, 3-36.

32. Cheng B., Munro O.Q., Marques H.M., Scheidt W.R. J. Am. Chem. Soc. 1997, 119, 10732-10742.

33. Shelnutt J.A., Song X.-Z., Ma J.-G., Jia S.-L., Jentzen W., Medforth C.J. Chem. Soc. Rev. 1998, 27, 31-41.

34. Rosa A., Ricciardi G., Baerends E.J., Romeo A., Scolaro L.M. J. Phys. Chem. A 2003, 107, 11468-11482.

35. Rosa A., Riccardi G., Baerends E.J. J. Phys. Chem. A 2006, 110, 5180-5190.

36. Kruk M.M., Starukhin A.S., Maes W. Macroheterocycles 2011, 4, 69-79.

37. De Luca G., Romeo A., Scolaro L.M., Ricciardi G., Rosa A. Inorg. Chem. 2007, 46, 5979-5988.

38. Presselt M., Dehaen W., Maes W., Klamt A., Martinez T., Beenken W.J.D., Kruk M.M. Phys. Chem. Chem. Phys. 2015, 17, 14096-14106.

39. Karotki A., Drobizhev M., Kruk M., Spangler C.W., Nickel E., Mamardashvili N., Rebane A. J. Opt. Soc. Am. B 2003, 20, 321-332.

40. Kruk M.M., Braslavsky S.E. Photochem. Photobiol. Sci. 2012, 11, 972-978.

41. Maes W., Ngo T.H., Rong G., Starukhin A.S., Kruk M.M., Dehaen W. Eur. J. Org. Chem. 2010, 4, 2576-2586.

42. Nguyen N.T., Hofkens J., Scheblykin I.G., Kruk M.M., Dehaen W. Eur. J. Org. Chem. 2014, 8, 1766-1777.

43. Nguyen N.T., Coutiño-Gonzalez E., Hofkens J., Scheblykin I.G., Dehaen W., Kruk M.M. Macroheterocycles 2014, 7, 240248.

44. Kruk M.M, Vershilovskaya I.V., Stefani S., Verstappen P., Ngo T.H., Scheblykin I.G., Dehaen W., Maes W. 9-th International Conference on Porphyrins and Phthalocyanines ICPP-9: Book of Abstracts, Nanjing, China, July 3-8, 2016, 422.
45. Kruk M.M., Vershilovskaya I.V., Ngo T.H., Scheblykin I.G., Dehaen W., Maes W. Trudy BGTU [Proceedings of Belarussian State Technological University (BSTU): Physics, Mathematics and Computer Science] 2016, 186(4), 16-20 (in Russ.)

46. Lindsey J.S., Wagner R.W. J. Org. Chem. 1989, 54, 828-836.

47. Kruk M.M., Braslavsky S.E. J. Phys. Chem. A 2006, 110, 3414-3425.

48. Gouterman M., Wagniere G., Snyder L.R. J. Mol. Spectrosc. 1963, 11, 108-127.

49. Gouterman M. Optical Spectra and Electronic Structure of Porphyrins and Related Rings. In: The Porphyrins, Vol. 3, (Dolphin D., Ed.), New York: Academic Press, 1978. p. 1-165.

50. Starukhin A.S., Kruk M.M., Gladkova O.L., Maes W. Macroheterocycles 2011, 4, 85-88.

51. Kruk M.M., Ngo T.H., Verstappen P., Starukhin A.S., Hofkens J., Dehaen W., Maes W. J. Phys. Chem. A 2012, 116, 1069510703.

52. Antonov L., Nedeltchava D. Chem. Soc. Rev. 2000, 29, $217-$ 227.

53. Kruk M.M., Starukhin A.S., Mamardashvili N.Z., Mamardashvili G.M., Ivanova Y.B., Maltseva O.V. J. Porphyrins Phthalocyanines 2009, 13, 1148-1158.

54. Gael V.I., Kuzmitsky V.A., Solovyov K.N. J. Appl. Spectrosc. 2000, 67, 696-702.

55. Haddad R.E.J., Gazeau S., Pecaut J., Marchon J.-C., Medforth C.J., Shelnutt J.A. J. Am. Chem. Soc. 2003, 125, 1253-1268.

56. Yamauchi S., Matsukawa Y., Ohba Y., Iwaizumi M. Inorg. Chem. 1996, 35, 2910-2914.

57. Liulkovich L.S., Kruk M.M. Trudy BGTU [Proceedings of Belarussian State Technological University (BSTU): Physics, Mathematics and Computer Science] 2015, 170(6), 63-67 (in Russ.).

58. Maes W., Amabilino D.B., Dehaen W. Tetrahedron 2003, 59, 3937-3943.

59. Chavan S.A., Maes W., Gevers L.E.M., Wahlen J., Vankelecom I.F.J., Jacobs P.A., Dehaen W., De Vos D.E. Chem. Eur. J. 2005, 11, 6754-6762.

60. Maes W., Vanderhaeghen J., Smeets S., Asokan C.V., Van Renterghem L.M., Du Prez F.E., Smet M., Dehaen W. J. Org. Chem. 2006, 71, 2987-2994.

61. Maes W., Dehaen W. Eur. J. Org. Chem. 2009, 4719-4752. 